\title{
GRADING OF DIAMOND POWDER
}

(Second Edition)

\section{COMMERCIAL STANDARD CS123-49}

[Supersedes CS123-45]

Effective Date for New Production From June 15, 1949

\section{A RECORDED VOLUNTARY STANDARD OF THE TRADE}

\section{UNITED STATES DEPARTMENT OF COMMERCE}

\author{
CHARLES SAWYER, Secretary
}




\section{COMMODITY STANDARDS}

Simplified Practice Recommendations and Commercial Standards are developed by manufacturers, distributors, and users in cooperation with the Commodity Standards Division of the National Bureau of Standards. The purpose of Simplified Practice Recommendations is to eliminate avoidable waste through the establishment of standards of practice for stock sizes and varieties of specific commodities that currently are in general production and demand. The purpose of Commercial Standards is to establish standard methods of test, rating, certification, and labeling of commodities, and to provide uniform bases for fair competition.

The adoption and use of a Simplified Practice Recommendation or Commercial Standard is voluntary. However, when reference to a Commercial Standard is made in contracts, labels, invoices, or advertising literature, the provisions of the standard are enforceable through usual legal channels as a part of the sales contract.

A Simplified Practice Recommendation or Commercial Standard originates with the proponent industry. The sponsors may be manufacturers, distributors, or users of the specific product. One of these three elements of industry submits to the Commodity Standards Division the necessary data to be used as the basis for developing a standard of practice. The Division, by means of assembled conferences or letter referenda, or both, assists the sponsor group in arriving at a tentative standard of practice and thereafter refers it to the other elements of the same industry for approval or for constructive criticism that will be helpful in making any necessary adjustments. The regular procedure of the Division assures continuous servicing of each effective Simplified Practice Recommendation and Commercial Standard, through review and revision, whenever, in the opinion of the industry, changing conditions warrant such action. Simplified Practice Recommendations and Commercial Standards are printed and made available by the Department of Commerce through the Government Printing Office.

\section{COMMERCIAL STANDARD FOR GRADING OF DIAMOND POWDER

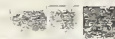

On September 19, 1944, a Recommended Commercial Standard for Grading of Diamond Powder was presented to those concerned for written acceptance. It was subsequently accepted by the trade, and promulgated by the United States Department of Commerce as Commercial Standard CS123-45.

On June 15, 1948, a revision recommended by the standing committee was circulated to producers, distributors, and users for written acceptance. Those concerned have since accepted and approved the commercial standard as shown herein.

Project Manager: F. W. Reynolds, Commodity Standards Division, National Bureau of Standards.

Technical Advisers: DR. LEwIS V. Judson, Metrology Division, and DR. H. InSLEY, Mineral Products Division, National Bureau of Standards. 


\title{
COMMERCIAL STANDARD CS123-49 \\ for \\ GRADING OF DIAMOND POWDER
}

\author{
(SECOND EDITION)
}

\section{PURPOSE}

1. The purpose of this commercial standard is to provide a nationally recognized standard for sizing of diamond powder, to provide a basis for understanding between purchasers and sellers as to the quality and particle size desired or supplied; and to provide a uniform method of guaranteeing conformance with the size designated.

\section{SCOPE}

2. This standard covers material, size designations, particle size and size range, amount of "fines," or particles smaller than the minimum for each designation, impurities, methods of sampling and inspection, and method of indicating compliance with this standard. ${ }^{1}$

\section{DEFINITIONS}

3. Particle size.-For the purpose of this standard the size of the particle is one-half the sum of its longest dimension and the maximum dimension at right angles to its longest dimension, both measurements taken on the face exposed to view in the microscopic field and expressed in microns.

4. Fines.-For the purpose of this standard a "fine" is any particle smaller than the minimum for any specified size.

\section{GENERAL REQUIREMENTS}

5. Material.-Diamond powder shall consist of crushed diamond or bort. It shall be graded for size as specified in tables 1 and 2 .

\section{DETAIL REQUIREMENTS}

6. Size ranges.--Size ranges and average particle size are given in tables 1 and 2. It is not intended that all manufacturers shall supply all grades listed. In case intermediate grades are supplied, the minimum and maximum sizes for any such grades shall be determined by mutual agreement between purchaser and seller, all other requirements of this standard to be unchanged.

6a. Average particle size.-The size designation shall be the average size of the particles as determined by microscopic methods, disregarding fines. In case of dispute, the range of particle size distribution

\footnotetext{
1 Nothing in the standard is to be taken to mean that diamond powder suppliers are prohibited from selling grades and sizes that are not in the standard specifications, so long as they are not represented as conforming to the commercial standard.
} 
shall approximate the normal probability curve, and the norm (maximum incidence) shall conform to the micron size of the size designations within a tolerance of not more than \pm 25 percent of the range.

7. Large particles and fines.-

7a. Micron sizes. - In sizes shown in table 1, no particles larger than the maximum specified in the particle size range shall be present. Particles smaller than the minimum shall not be present in an amount numerically greater than 50 percent and shall not constitute more than 3 percent of the total weight of powder.

7b. Sieve sizes.-In sizes shown in table 2, the U. S. Standard Sieves shall be used. The sizes attained through careful sieving are subject to the variations of the U. S. Standard Sieves. Finer particles shall not be present in an amount numerically greater than 10 percent of the total number of particles.

TABLE 1. Micron sizes

\begin{tabular}{|c|c|}
\hline Particle size & $\begin{array}{c}\text { Average par- } \\
\text { ticle size } \\
\text { (designation) }\end{array}$ \\
\cline { 2 - 2 }$\#$ Microns & Microns \\
$\# \mathrm{~m}$ 2 and finer & 1 \\
$\#$ 1 to 5 & 3 \\
$\# \mathrm{~m}$ 4 to 8 & 6 \\
$\# \mathrm{~m}$ 6 to 12 & 9 \\
$\# \mathrm{~m}$ 8 to 22 & 30 \\
$\# \mathrm{~m} 20$ to 40 & 45 \\
$\# \mathrm{~m} 30$ to 60 & 60 \\
$\# \mathrm{~m} 35$ to 85 & \\
\hline
\end{tabular}

TABLE 2. Sieve sizes

\begin{tabular}{|c|c|}
\hline $\begin{array}{l}\text { U. S. Standard } \\
\text { Sieve No. size }\end{array}$ & $\begin{array}{l}\text { A verage par- } \\
\text { ticle size } \\
\text { (designation) }\end{array}$ \\
\hline $\begin{array}{lr}\# \mathrm{~s} & 230 \text { to } .325 \\
\# \mathrm{~S} & 170 \text { to } 230 \\
\# \mathrm{~s} & 120 \text { to } 170 \\
\# \mathrm{~s} & 100 \text { to } 120 \\
\# \mathrm{~s} & 80 \text { to } 100 \\
\# \mathrm{~S} & 60 \text { to } 80 \\
\# \mathrm{~s} & 40 \text { to } 60\end{array}$ & $\begin{array}{c}\text { Microns } \\
74 \\
106 \\
150 \\
193 \\
230 \\
302 \\
473\end{array}$ \\
\hline
\end{tabular}

\section{Impurities.-}

8a. Micron sizes.-A maximum of 5 percent by weight of impurities is permitted in sizes shown in table 1 .

8b. Sieve sizes. - A maximum of 2 percent by weight of impurities is permitted in sizes shown in table 2 .

\section{METHODS OF SAMPLING AND INSPECTION}

9. Sampling.-Lots of 100 carats or less shall be quartered ${ }^{2}$ to obtain a sample of the desired size. Lots larger than 100 carats may be

${ }^{2}$ Sampling by quartering.-The quantity of powdered material to be quartered is thoroughly mixed and formed into a symmetrical heap on a sheet of glazed paper by alternately raising and lowering opposite edges of the paper. By the use of a spatula, the heap of material is then divided approximately into quarters by two straight lines intersecting at right angles at the center of the heap. Two opposite quarters are removed and the two remaining quarters are mixed and divided as before, repeating the cycle until a sample of the desired size remains. 
thoroughly mixed and a representative sample of about 100 carats taken and quartered.

10. Identification.-Diamond powder can be identified, and the presence of impurities can be detected by a competent laboratory familiar with petrographic methods of microscopic examination.

11. Particle size.-A sample weighing 0.1 carat or less, obtained by quartering as described in paragraph 9 , shall be placed on a glass slide and moistened with a drop of pine oil or other adequate dispersant, then thoroughly mixed and covered with a cover glass. Excess oil is pressed out and removed by blotting with absorbent paper. The slide is then placed under a microscope having a suitable ocular and objective. The sizes of the particles are determined as specified in paragraph 3 by measuring with a micrometer eyepiece or by means of dividers on a photomicrograph of known enlargement.

11a. The entire slide shall be examined systematically for particles larger than the maximum for the size designated. If any particle is found that exceeds the maximum specified for the size, the powder fails to meet the requirements of this standard. If the powder is not rejected for that reason, not less than four randomly selected fields containing a total of not less than 400 particles shall be examined. Several particles near the minimum size specified for the size shall be measured as specified in paragraph 3 and used for reference in counting fines. The total number of particles and the number of fines are recorded. If the number and size of the fines indicate a possibility that the weight of fines represents as much as 3 percent of the total weight, the percentage by weight shall be determined by the procedure given in paragraph 12.

$11 \mathrm{~b}$. When a determination of the norm as specified in paragraph $6 \mathrm{a}$ is required, the particles shall be grouped in an appropriate number of groups of equal size range and counted to determine the number of particles in each size group. Disregard fines. (See ASTM Manual on Presentation of Data.)

12. Amount of fines.-The amount of fines in sieve sizes shall be determined by sieving. If the microscopic examination in micron sizes indicates that fines may be present in an amount greater than 3 percent by weight, the percentage is determined by the following procedure:

12a. A 5-g (25 carats) quartered sample of the diamond powder is weighed accurately on an analytical balance. The sample is then mixed with $100 \mathrm{ml}$ of a 0.1 -percent-gelatin (USP) solution (in distilled water), the $\mathrm{pH}$ of which has been adjusted with sodium carbonate to $9 \pm 1$. This slurry is stirred and shaken for at least 1 hour. It is then made up to exactly $250 \mathrm{ml}$ with 0.1 -percent-gelatin solution $(\mathrm{pH} 9 \pm 1)$ in a 250-ml cylindrical graduate and again shaken and stirred.

$12 \mathrm{~b}$. The cylinder is set at rest and kept at a temperature of $25^{\circ} \pm 1^{\circ}$ $\mathrm{C}$ for the length of time indicated in table 3 , the time of sedimentation beginning when the cylinder is set at rest. At the end of the sedimentation time, a 5 -ml portion is withdrawn from a point exactly 5 $\mathrm{cm}$ below the surface of the liquid with a pipette calibrated to contain $5 \mathrm{ml}$. A mark should be made on the pipette to facilitate $5-\mathrm{cm}$ immersion of the tip. The pipette remains stationary and is not lowered to follow changes in level of liquid in the graduate. 
12c. The withdrawn portion is discharged into a tared beaker or weighing bottle. The pipette is rinsed with warm distilled water and the rinsings added to the beaker. Evaporate the water and dry in an oven at approximately $105^{\circ} \mathrm{C}$. Cool in a desiccator and weigh.

$12 d$. Subtract the weight of the dried gelatin $(0.0050 \mathrm{~g})$ from the total weight of the dry residue from method $12 \mathrm{c}$ to obtain the net weight of fines in the withdrawn portion. Multiply this weight by 50 to obtain the weight of fines in the original sample and compute percent by weight, or use the formula:

Net weight of fines

Percentage of fines by weight $=\frac{250}{5} \times \frac{\text { in withdrawn portion }}{\text { Weight of sample }} \times 100$.

Table 3. Sedimentation time

\begin{tabular}{|c|c|c|c|}
\hline \multirow{2}{*}{$\begin{array}{l}\text { Minimum } \\
\text { grain size } \\
\text { (microns) }\end{array}$} & \multicolumn{3}{|c|}{ Sedimentation time at $25^{\circ} \mathrm{C}$} \\
\hline & Hours & Minutes & Seconds \\
\hline $\begin{array}{r}1 \\
4 \\
6 \\
8 \\
20 \\
30 \\
35\end{array}$ & $\begin{array}{c}9 \\
-1\end{array}$ & $\begin{array}{r}15 \\
34 \\
15 \\
8 \\
1 \\
\\
\end{array}$ & $\begin{array}{l}30 \\
45 \\
10 \\
25 \\
21 \\
37 \\
27\end{array}$ \\
\hline
\end{tabular}

12e. Amount of fines (alternate method).-Laboratories equipped with air analyzers such as the Roller Particle Size Analyzer may determine the weight of fines by air separation. In cases of controversy, the separated portion and residue shall be inspected microscopically to check the completeness of the separation.

13. Impurities.-If the microscopic inspection shows the presence of impurities in amounts greater than minute traces, the amount shall be determined by digesting with acid an accurately weighed sample of approximately 5 carats (obtained by quartering a representative sample as described in paragraph 9). (See notes 1, 2, and 3 on page 5.) Normally only total impurities are determined (see note 5).

13a (1). If oil or other organic matter is present, the 5-carat sample shall be digested with 5 to $10 \mathrm{ml}$ of hot bichromate cleaning solution (see note 4). After the digestion is judged complete, the diamond powder shall be settled by centrifuging, and the cleaning solution decanted without mechanical loss of diamond powder. The powder is then washed with not less than five $10-\mathrm{ml}$ portions of distilled water, centrifuged, and decanted between washings. The final decanted portion of water should be colorless. The powder is then dried to constant weight in an oven at approximately $105^{\circ} \mathrm{C}$. The percentage loss in weight is computed.

13a (2). After weighing, the washed powder is quartered to obtain a 0.1-carat or smaller sample for microscopic examination. This sample shall be examined microscopically to detect the presence of impurities not removed by the acid treatment. Complete removal of 
organic material shall be shown. If other types of impurities are also absent, digestion with other acids is unnecessary. If other impurities are present, the residue from taking the 0.1-carat sample for the microscopic examination is accurately weighed and other impurities determined by methods $13 \mathrm{~b}$ and $13 \mathrm{c}$, or a new 5-carat sample may be taken and digested with bichromate cleaning solution, settled, decanted, and washed for use in methods $13 \mathrm{~b}$ and 13c. (See note 5.)

$13 \mathrm{~b}$. If metal particles or metal salts are present (in the absence of organic material), a sample of the diamond powder shall be digested at room temperature with 5 to $10 \mathrm{ml}$ of 10-percent hydrochloric acid, settled, decanted, and washed, followed by digestion with 5 to $10 \mathrm{ml}$ of 10-percent nitric acid, after which it is again settled, washed at least three times, dried, and the loss in weight determined as above. A microscopic examination of a 0.1-carat or smaller quartered sample of the washed powder shall show complete removal of the metal and metal salts. The percentage of metallic impurities shall be computed on the powder in its original condition.

$13 \mathrm{c}(1)$. If the microscopic examination shows the presence of siliceous material such as glass or sand, washed powder from method $13 \mathrm{~b}$ may be used for analysis if not less than 4 carats remain; or a new 5-carat sample may be taken and treated as in methods $13 \mathrm{a}$ and $13 \mathrm{~b}$ to remove organic and metallic impurities.

13c (2). Transfer the accurately weighed sample of not less than 4 carats to a suitably sized clean platinum dish or crucible, weighed with cover. Moisten the sample with a few milliliters of water, add 10 to 15 drops of diluted sulfuric acid $(1+1)$ and $10 \mathrm{ml}$ of hydrofluoric acid (40 percent). Evaporate on a sand bath or hot plate to fumes of sulfuric acid. Care should be taken to avoid loss by spattering. Cool the dish, add a few drops of water, $5 \mathrm{ml}$ of hydrofluoric acid (40 percent), and repeat the evaporation to fumes. Continue the heating until all sulfuric acid and sulfates have been expelled. Cover the dish, transfer to a desiccator, cool, and weigh. The loss in weight is recorded as silica $\left(\mathrm{SiO}_{2}\right)$ and the percentage computed on the original weight of powder.

$13 \mathrm{~d}$. The sum of the percentage loss in weight in methods $13 \mathrm{a}, 13 \mathrm{~b}$, and $13 \mathrm{c}$ is reported as "percentage of total impurity."

Note 1.-Experienced microscopists can often estimate with some accuracy by inspection alone the percentage of impurities. Except when inspecting for referee cases or court evidence, the microscopist may omit the chemical determinations if he is certain by inspection that the percentage is below the specified maximum.

Note 2.-The presence of large amounts of foreign material usually interferes seriously with close grading. For that reason, powders containing high percentages of foreign material will often be rejected because they do not fall within the size ranges shown in tables 1 and 2 . If the powder is rejected for that reason, it may be considered unnecessary to make a quantitative determination of the impurities present. In such cases, unless the laboratory is specifically instructed to make determination, a report may state the cause for rejection and merely indicate that high percentages of impurities were shown by the microscopic examination.

Note 3.-In the absence of graphite, organic material, carbonates, and carbides, or after their removal, laboratories equipped for and 
skilled in the determination of carbon by combustion may determine the diamond content as carbon and compute impurities by difference. As relatively small samples are used for carbon determination, great care must be taken in quartering and weighing the sample.

NoTE 4.-The bichromate cleaning solution is made by adding one liter of reagent grade concentrated sulfuric acid to 35-ml saturated solution of potassium bichromate, chemically pure, in distilled water. Add the acid to the bichromate solution slowly, stirring constantly with a glass rod.

Note 5.-When more than one type of impurity is observed the necessary digestions and washing may be conducted on the same sample without intermediate drying and weighing, total impurities being reported. In all cases when organic matter is present, treatment with bichromate cleaning solution should precede treatment with other acids. Whenever microscopic examination shows incomplete removal of any impurity, the determination shall be repeated on a new sample by using a larger amount of acid or longer digestion time, as appears necessary.

\section{IDENTIFICATION}

14. It is recommended that manufacturers declare compliance with this standard by means of the following statement on labels, invoices, sales literature, etc.:

The manufacturer declares that this diamond powder is in conformance with all requirements of Commercial Standard CS123-49, as developed by the trade under the procedure of the National Bureau of Standards, and issued by the United States Department of Commerce.

Particle size

\section{EFFECTIVE DATE}

15. Having been passed through the regular procedure of the Commodity Standards Division, and approved by the acceptors hereinafter listed, this commercial standard was issued by the United States Department of Commerce, effective from June 15, 1949.

\section{EDWIN W. ELY}

\section{Chief, Commodity Standards Division}

\section{HISTORY OF PROJECT}

16. On June 27, 1944, at the instance of the Miscellaneous Minerals Division of the War Production Board, a meeting of producers of diamond powder adopted a proposed commercial standard for grading ef diamond powder. This was submitted on July 11, 1944, to leading users of the product and interested Government agencies for constructive comment. Following adjustment of the proposal in agreement with comment, the recommended commercial standard was circulated for written acceptance on September 19, 1944. On March 6,1945 , it was announced that those concerned had accepted and approved the standard for promulgation by the United States Department of Commerce, through the National Bureau of Standards. The 
standard, designated as CS123-45, was effective for new production from May 5, 1945.

17. On January 19, 1948, a revision of the standard developed by the Industrial Diamond Association of America, Inc., was submitted to the standing committee for review. Upon recommendation of the majority of that committee, the recommended revision was circulated to the industry for written acceptance on June 15, 1948. Because of some differences of opinion that developed subsequently, an industry meeting was held in New York City on September 22, 1948, at which some further adjustments of the specification were made. On May 16,1949 , acceptances having been received representing a satisfactory volume of business, and in the absence of active opposition, the establishment of the revision was announced.

\section{STANDING COMMITTEE}

18. The following individuals comprise the membership of the standing committee, which is to review, prior to circulation for acceptance, revisions proposed to keep the standard abreast of progress. Comment concerning the standard and suggestions for revision may be addressed to any member of the committee or to the Commodity Standards Division, National Bureau of Standards, which acts as secretary for the committee.

HeRBert Insley (Chairman), National Bureau of Standards, Washington $25, \mathrm{D}$. C.

Bert Brenner, Diamond Development Company of America, Inc., 1650 Broadway, New York 19, N. Y.

Nathan Salzman, General Diamond Co., 576 Fifth Avenue, New York 19, N. Y. F. E. Koeber, J. K. Smit \& Sons, Inc., 157 Chambers Street, New York 7, N. Y. A. A. Klein, Norton Co., Worcester, Mass.

E. W. Weimar, Jr., Adamant Tool Co., Division of Wheel Trueing Co., 657 Bloomfield Avenıe, Bloomfield, N. J.

Horace Wincheld, Sheffield Scientific School, Yale University, New Haven, Conn. C. B. Shopmyer, Wire Section, Works Laboratory, General Electric Co., 1 River Road, Schenectady, N. Y.

G. P. Brockway, American Optical Co., 14 Mechanic Street, Southbridge, Mass. Elmer C. Swenson, Johnson Steel \& Wire Co., 53 Wiser Avenue, Worcester, Mass. (representing Fine and Specialty Wire Manufacturers' Association). 



\section{ACCEPTANCE OF COMMERCIAL STANDARD}

If acceptance has not previously been filed, this sheet properly filled in, signed, and returned will provide for the recording of your organization as an acceptor of this commercial standard.

\section{Date}

Commodity Standards Division,

National Bureau of Standards,

Washington 25, D. C.

Gentlemen:

We believe that the Commercial Standard CS123-49 constitutes a useful standard of practice, and we individually plan to utilize it as far as practicable in the

$\begin{array}{llll}\text { production }^{1} & \text { distribution }^{1} & \text { purchase }^{1} & \text { testing }^{1}\end{array}$

of diamond powder. We reserve the right to depart from it as we deem advisable.

We understand, of course, that only those articles which actually comply with the standard in all respects can be identified or labeled as conforming thereto.

Signature of authorized officer

(In ink)

(Kindly typewrite or print the following lines)

Name and title of above officer

Organization

(Fill in exactly as it should be listed)

Street address

City, zone, and State

1 Underscore which one. Please see that separate acceptances are filed for all subsidiary companies and affiliates which should be listed separately as acceptors. In the case of related interests, trade associations, trade papers, etc., desiring to record their general support, the words "General Support" should be added after the signature. 


\section{TO THE ACCEPTOR}

The following statements answer the usual questions arising in connection with the acceptance and its significance:

1. Enforcement.-Commercial standards are commodity specifications voluntarily established by mutual consent of those concerned. They present a common basis of understanding between the producer, distributor, and consumer and should not be confused with any plan of governmental regulation or control. The United States Department of Commerce has no regulatory power in the enforcement of their provisions, but since they represent the will of the interested groups as a whole, their provisions through usage soon become established as trade customs, and are made effective through incorporation into sales contracts by means of labels, invoices, and the like.

2. The acceptor's responsibility.-The purpose of commercial standards is to establish for specific commodities, nationally recognized grades or consumer criteria and the benefits therefrom will be measurable in direct proportion to their general recognition and actual use. Instances will occur when it may be necessary to deviate from the standard and the signing of an acceptance does not preclude such departures; however, such signature indicates an intention to follow the commercial standard where practicable, in the production, distribution, or consumption of the article in question.

3. The Department's responsibility.-The major function performed by the Department of Commerce in the voluntary establishment of commercial standards on a Nation-wide basis is fourfold: first, to act as an unbiased coordinator to bring all interested parties together for the mutually satisfactory adjustment of trade standards; second, to supply such assistance and advice as past experience with similar programs may suggest; third, to canvass and record the extent of acceptance and adherence to the standard on the part of producers, distributors, and users; and fourth, after acceptance, to publish and promulgate the standard for the information and guidance of buyers. and sellers of the commodity.

4. Announcement and promulgation.-When the standard has been endorsed by a satisfactory majority of production or consumption in the absence of active valid opposition, the success of the project is announced. If, however, in the opinion of the standing committee or the Department of Commerce, the support of any standard is inadequate, the right is reserved to withhold promulgation and publication. 


\section{ACCEPTORS}

The organizations listed below have individually accepted this standard for use as far as practicable in the production, distribution, purchase, or testing of diamond powder. In accepting the standard, they reserved the right to depart therefrom as they individually deem advisable. It is expected that articles which actually comply with the requirements of this standard in all respects will be regularly identified or labeled as conforming thereto, and that purchasers will require such specific evidence of conformity.

\section{ASSOCIATIONS \\ (General Support)}

Fine \& Specialty Wire Manufacturers' Association, Washington, D. C.

Industrial Diamond Association of America, Inc., New York, N. Y.

\section{FIRMS}

Abrasive Dressing Tool Co., Detroit, Mich. Adamant Tool Co., Eastern Division of Wheel Trueing Tool Co., Bloomfield, N. J.

Ajax Industrial Supplies, Inc., Ft. Wayne, Ind.

American Abrasive Co., Westfield, Mass.

American Boarts Crushing Co., Inc., New York, N. Y.

American Diamond Tool \& Gauge Co., Detroit, Mich.

American Optical Co., Southbridge, Mass.

American Steel \& Wire Co., Cleveland, Ohio. Antwerp Industrial Diamond Co., New York, N. Y.

Balloffet Dies \& Nozzle Co., Inc., Guttenberg, N. J.

Bowser Morner Testing Laboratories, Dayton, Ohio.

Brenon, Inc., New Brunswick, N. J

Bulova Watch Co., Woodside, L. I., N. Y.

Callite Tungsten Corp., New York, N. Y.

Camden Wire Co., Inc., Camden, N. Y.

Capital Diamond Cutters, Inc., New York, N. Y.

Carborundum Co., The, Niagara Falls, N. Y. Caterpillar Tractor Co., San Leandro, Calif. Champion Diamond Co., Inc., New York, N. Y.

Crafts, Arthur A., Co., Inc., Boston, Mass.

Crescent Insulated Wire \& Cable Co., Trenton. N. J.

Danforth, C. W. Co. The, Youngstown, Ohio

Detroit Testing Laboratory, The, Detroit, Mich.

Diamond-Detroit, Inc., Detroit, Mich.

Diamond Distributors, Inc., New York, N. Y.

Diamond Drill Carbon Co., The, New York N. Y.

Diamond Pointed Tool Co., Atlantic Highlands, N. J.

Diamond Tool \& Die Works, Hartford, Conn

Diamond Tool Research Co., Division of Baumgold Bros., Inc., New York, N. Y.

Driver, Wilbur B., Co., Newark, N.'J.

Eastman Kodak Co., Rochester, N. Y.

Ekroth Laboratories, Inc., Brooklyn, N. Y.

Elgin National Watch Co., Aurora, Ill.

General Diamond Co., New York, N. Y.

Gilbert \& Bennett Manufacturing Co., The, Georgetown, Conn.

Gilman Engineering \& Manufacturing Corp., Janesville, Wis.

Gilmore, F. F., \& Co., Inc., Boston, Mass.

Hamilton Watch Co., Lancaster, Pa.

Heald Machine Co., The, Worcester, Mass.

Hoskins Manufacturing Co., Detroit, Mich.

Hudson Wire Co., Ossining, N. Y.

Indiana Wire Die Co., Fort Wayne, Ind.

Industrial Diamond Co., Detroit, Mich.
Johnson Steel \& Wire Co., Inc., Worcester, Mass.

Karelsen, E., Inc., New York, N. Y.

Kelly Wire Die Corp., New York, N. Y.

Landau, A., Co., Philadelphia, Pa.

Lincoln Electric Co., Cleveland, Ohio.

Lindsay Wire Weaving Co., The, Cleveland, Ohio.

Meridian Engineering Corp., Chicago, Ill.

Mildrum, W. W., Jewe Co., The, Last Berlin, Conn.

National Diamond Hone \& Wheel Co., New York, N. Y.

National Diamond Laboratory, New York, N. Y.

National-Standard Co., Niles, Mich.

National Tinsel Manufacturing Co., Manitowoc, Wis.

New England High Carbon Wire Co., Mill bury, Mass.

New York Wire Cloth Co., York, Pa.

Newark Wire Cloth Co., Newark, N. J.

Norton Co., Worcester, Mass

Parser, A. G., Inc., New York, N. Y.

Precision Diamond Tool Co., Elgin, Ill.

Radio Corp. of America, RCA Victor Division, Camden, N. J.

Roebling's, John A., Sons Co., Trenton, N. J.

Roller, P. S., Hyattsville, Má.

Sangamo Electric Co., Springfield, Ill.

Service Diamond Tool Co., Ferndale, Mich.

Sinsz, Philip, Co., The, New York, N. Y.

Smit, Anton, \& Co., Inc., New York, N. Y.

Smit, J. K., \& Sons, Inc., New York, N. Y

Smit. J. K., \& Sons of Michigan, Inc., Detroit, Mich.

Spandel, H. R., Inc., New York, N. Y. (General support.)

Standard Diamond Tool Corp., New York, N. Y.

Star Dental Manufacturing Co., Philadelphia, $\mathrm{Pa}$.

Stewart, Lynn, Diamond Products, Fort Wayne, Ind.

Superior Abrasive Laboratories, White Plains, N. Y.

Timken Roller Bearing Co., The, Canton, Ohio.

Tyler, W. S., Co., The, Cleveland, Ohio.

Union Wire Rope Corp., Kansas City, Mo.

United States Industrial Diamond Corp. New York, N. Y.

United Wire \& Supply Corp., Providence, R. I. Universal Diamond Co., New York, N. Y.

Vascoloy-Ramet Corp., Waukegan, Ill.

Vieyra Co., The, New York, N. Y.

Westinghouse Electric Corp., East Pittsburgh, Pa.

Weston Electrical Instrument Corp., Newark, N. J. (General support.)

Wheel Trueing Tool Co., Detroit, Mich.

Yale University. Brush Mineralogical Laboratory, New Haven, Conn. (General support.)

\section{U. S. GOVERNMENT}

Agriculture. United States Department of, Washington, D. C. 


\section{COMMERCIAL STANDARDS}

CS No.

0-40. Commercial standards and their value to business (third edition).

1-42. Clinical thermometers (third edition).

2-30. Mopsticks,

3-40. Stoddard solvent (third edition).

4-29. Staple porcelain (all-clay) plumbing fixtures.

5-46. Pipe nipples; brass, copper, steel. and wrought-iron (second edition ).

6-31. Wrought-iron pipe nipples (second edition) Superseded by CS5-46.

7-29. Standard weight malleable iron or steel screwed unions.

8-41. Gage blanks (third edition).

9-33. Builders' template hardware (second edition).

10-29. Brass pipe nipples. Superseded by CS5-46.

11-41. Moisture regains of cotton yarns (second edition).

12-48. Fuel oils (sixth edition).

13-44. Dress patterns (fourth edition).

14-43. Boys' button-on waists, shirts, junior and sport shirts (made from woven fabrics) (third edition).

15-46. Men's pajama sizes (made from woven fabrics) (third edition).

16-29. Wall paper.

17-47. Diamond core drill fittings (fourth edition).

18-29. Hickory golf shafts.

19-32. Foundry patterns of wood (second edition).

20-49. Vitreous china plumbing fixtures (fifth edition).

21-39. Interchangeable ground-glass joints, stopcocks, and stoppers (fourth edition).

22-40. Builders' hardware (nontemplate) (second edition).

23-30. Feldspar.

24-43. Screw threads and tap-drill sizes.

25-30. Special screw threads. Superseded by CS24-43.

26-30. Aromatic red cedar closet lining.

27-36. Mirrors (second edition).

28-46. Cotton fabric tents, tarpaulins, and covers (second edition).

29-31. Staple seats for water-closet bowls.

30-31. Colors for sanitary ware. (With drawn as commercial standard, March 15, 1948.)

31-38. Wood shingles (fourth edition).

$32-31$. Cotton cloth for rubber and pyroxylin coating.

33-43. Knit underwear (exclusive of rayon) (second edition)

34-31. Bag, case, and strap leather.

35-47. Hardwood plywood (third edition)

36-33. Fourdrinier wire cloth (second edition).

37-31. Steel bone plates and screws.

38-32. Hospital rubber sheeting.

39-37. Wool and part wool blankets (second edition). (Withdrawn as commercial standard, July 14, 1941).

40-32. Surgeons' rubber gloves.

41-32. Surgeons' latex gloves.

42-49. Structural fiber insulating board (fourth edition)

43-32. Grading of sulphonated oils.

44-32. Apple wraps.

45-48. Douglas fir plywood (eighth edition).

46-49. Hosiery lengths and sizes (fourth edition).

47-34. Marking of gold-filled and rolledgold-plate articles other than watchcases.
CS No.

48-40. Domestic burners for Pennsylvania anthracite (underfeed type) (second edition).

49-34. Chip board, laminated chip board and miscellaneous boards for bookbinding purposes.

50-34. Binders' boards for bookbinding and other purposes.

51-35. Marking articles made of silver in combination with gold.

52-35. Mohair pile fabrics (100-percent mohair plain velvet, 100 -percent mohair plain frieze, and 50-percent mohair plain frieze)

53-35. Colors and finishes for cast stone. 54-35. Mattresses for hospitals.

55-35. Mattresses for institutions.

56-49. Oak flooring (third edition)

57-40. Book cloths, buckrams, and impregnated fabrics for bookbinding purposes except library bindings (second edition).

58-36. Woven elastic fabrics for use in overalls (overall elastic webbing).

59-44. Textiles-testing and reporting (fourth edition)

60-48. Hardwood dimension lumber (second edition).

61-37. Wood-slat venetian blinds.

62-38. Colors for kitchen accessories.

63-38. Colors for bathroom accessories.

64-37. Walnut veneers.

65-43. Methods of analysis and of reporting fiber composition of textile products (second edition).

66-38. Marking of articles made wholly or in part of platinum.

67-38. Marking articles made of karat gold.

68-38. Liquid hypochlorite disinfectant, deodorant, and germicide.

69-38. Pine oil disinfectant.

70-41. Phenolic disinfectant (emulsifying type) (second edition) (published with CS71-41).

71-41. Phenolic disinfectant (soluble type) (second edition) (published with CS70-41).

72-38. Household insecticide (liquid spray type).

73-48. Old growth Douglas fir, Sitka spruce and Western hemlock standard stock doors (fourth edition).

74-39. Solid hardwood wall paneling.

75-42. Automatic mechanical draft oil burners designed for domestic installations (second edition).

76-39. Hardwood interior trim and molding.

77-48. Enameled cast-iron plumbing fixtures (second edition).

78-40. Ground-and-polished lenses for sun glasses (second edition) (published with CS79-40).

79-40. Blown, drawn, and dropped lenses for sun glasses (second edition) (published with CS78-40).

80-41. Electric direction signal systems other than semaphore type for commercial and other vehicles subject to special motor vehicle laws (after market).

81-41. Adverse-weather lamps for vehicles (after market).

82-41. Inner-controlled spotlamps for vehicles (after market).

83-41. Clearance, marker, and identification lamps for vehicles (after market).

84-41. Electric tail lamps for vehicles (after market).

85-41. Electric license-plate lamps for vehicles (after market)

86-41. Electric stop lamps for vehicles (after market). 
CS No.

87-41. Red electric warning lanterns,

88-41. Liquid burning flares.

89-40. Hardwood stair treads and risers.

90-49. Power cranes and shovels.

91-41. Factory-fitted Douglas tir entrance doors.

92-41. Cedar, cypress and redwood tank stock lumber.

93-41. Portable electric drills (exclusive of high frequency).

94-41. Calking lead.

96-41. Lead traps and bends.

97-42. Electric supplementary driving and passing lamps for vehicles (after market)

99-42. Gas floor furnaces-gravity circulating type.

100-47. Porcelain-enameled steel utensils (third edition).

101-43. Flue-connected oil-burning space heaters equipped with vaporizing pot-type burners.

102- . (Reserved for Diesel and fuel-oil engines).

103-48. Rayon jacquard velour (with or without other decorative yarn) (second edition).

104-49. Warm-air furnaces equipped with vaporizing-type oll burners (third edition).

105-48. Mineral wool insulation for low-

106-44. Boys' pajama sizes (woven fabrics) (second edition)

107-45. Commercial electric-refrigeration condensing units (second edition). (Withdrawn as commercial standard, September 4, 1947.)

108-43. Treading automobile and truck tires.

109-44. Solid-fuel-burning forced-air furnaces.

110-43. Tire repairs-vulcanized (passenger, truck, and bus tires).

111-43. Earthenware (vitreous-glazed) plumbing fixtures.

112-43. Homogeneous fiber wallboard.

113-44. Oil-burning floor furnaces equipped with vaporizing pot-type burners.

114-43. Hospital sheeting for mattress protection.

115-44. Porcelain-enameled tanks for domestic use.

116-44. Bituminized-fibre drain and sewer pipe.

117-49. Mineral wool insulation for heated industrial equipment (second edition).

118-44. Marking of jewelry and novelties of silver.

(E) 119-45.1 Dial indicators (for linear measurements)

120-48. Standard stock ponderosa pine doors

121-45. Women's slip sizes (woven fabrics)
95-41. Lead pipe.

98-42. Artists' oil paints. (third edition).

CS No.

122-45. Western hemlock plywood.

123-49. Grading of diamond powder (second edition).

(E) 124-45.1 Master disks.

125-47. Prefabricated homes (second edition).

126-45. Tank mounted air compressors.

127-45. Self-contained mechanically refrigerated drinking water coolers.

128-45. Men's sport shirt sizes-woven fabrics (other than those marked with regular neckband sizes).

129-47. Materials for safety wearing apparel (second edition).

130-46. Color materials for art education in schools.

131-46. Industrial mineral wool products, all types-testing and reporting.

132-46. Hardware cloth.

133-46. Woven wire netting.

134-46. Cast aluminum cooking utensils (metal composition)

135-46. Men's shirt sizes (exclusive of work shirts).

136-46. Blankets for hospitals (wool, and wool and cotton).

137-46. Size measurements for men's and boys' shorts (woven fabrics).

138-47. Insect wire screening.

139-47. Work gloves.

140-47. Testing and rating convectors

141-47. Sine bars, blocks, plates, and fixtures.

142-47. Automotive lifts.

143-47. Standard strength and extra strength perforated clay pipe.

144-47. Formed metal porcelain enameled sanitary ware.

145-47. Testing and rating hand-fired hot water supply boilers.

146-47. Gowns for hospital patients.

147-47. Colors for molded urea plastics.

148-48. Men's circular flat and rib knit rayon underwear.

149-48. Utility type house dress sizes.

150-48. Hot-rolled rail steel bars (produced from Tee-section rails).

151-48. Body measurements for the sizing of apparel for infants, babies, toddlers, and children (for the knit underwear industry).

152-48. Copper naphthenate wood-preservative.

153-48. Body measurements for the sizing of apparel for girls (for the knit underwear industry).

154- . (Reserved for wire rope).

155-49. Body measurements for the sizing of apparel for boys (for the knit underwear industry).

156-49. Colors for polystyrene plastics.

157-49. Ponderosa pine and sugar pine plywood.

158-49. Model forms for girls' apparel.

159-49. Sun glass lenses made of ground and polished plate glass thereafter thermally curved.

Notrce.-Those interested in commercial standards with a view toward accepting them as a basis of everyday practice may secure copies of the above standards, while the supply lasts, by addressing the National Bureau of Standards, Washington 25, D. C.

${ }^{1}$ Where "(E)" precedes the CS number, it indicates an emergency commercial standard, drafted under war conditions with a view toward early revision. 
